\title{
Nutrition, Metabolism and Cardiovascular Diseases \\ CA.ME.LI.A. An epidemiological study on the prevalence of cardiovascular, metabolic, liver and autoimmune diseases in Northern Italy \\ --Manuscript Draft--
}

\begin{tabular}{|c|c|}
\hline Manuscript Number: & NMCD-D-20-01282R1 \\
\hline Article Type: & Research Paper \\
\hline Keywords: & $\begin{array}{l}\text { Study population; Diabetes; cardiovascular risk; Metabolic Syndrome; Obesity; liver } \\
\text { disease; epidemiology }\end{array}$ \\
\hline Corresponding Author: & $\begin{array}{l}\text { Franco Folli } \\
\text { Milan, ITALY }\end{array}$ \\
\hline First Author: & Monica Bignotto \\
\hline \multirow[t]{14}{*}{ Order of Authors: } & Monica Bignotto \\
\hline & Michele Dei Cas \\
\hline & Rita Paroni \\
\hline & Elena Bianco \\
\hline & Paola Zermiani \\
\hline & Maria Grazia Gangale \\
\hline & Valentina Zadro \\
\hline & Margherita Maregatti \\
\hline & Alessandra Piagnani \\
\hline & Antonio Russo \\
\hline & Damiano Baldassarre \\
\hline & Franco Folli \\
\hline & Pier Maria Battezzati \\
\hline & Massimo Zuin \\
\hline Abstract: & 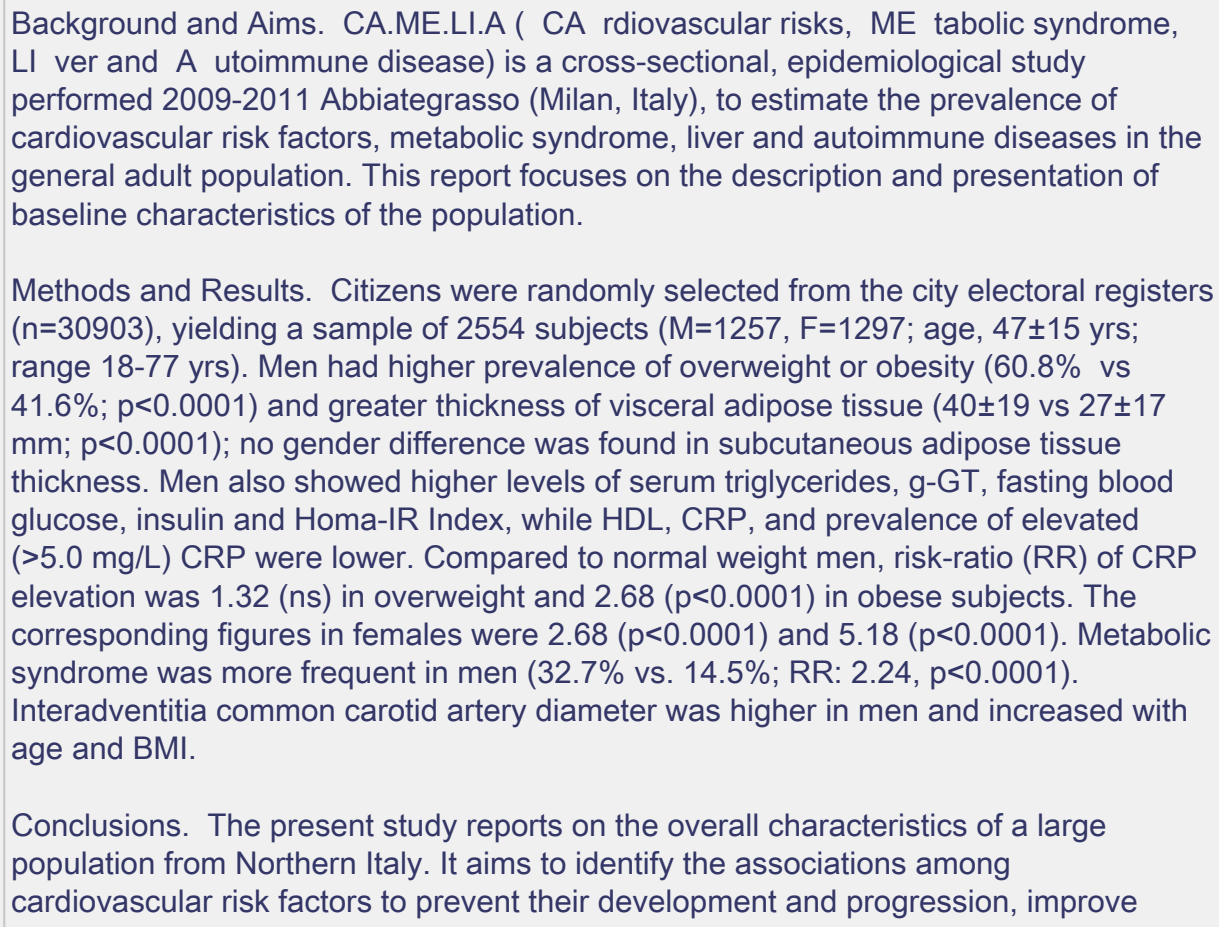 \\
\hline
\end{tabular}


healthy lifestyle, identify subjects liable to pharmacological interventions.

Powered by Editorial Manager ${ }^{\circledR}$ and ProduXion Manager ${ }^{\circledR}$ from Aries Systems Corporation 


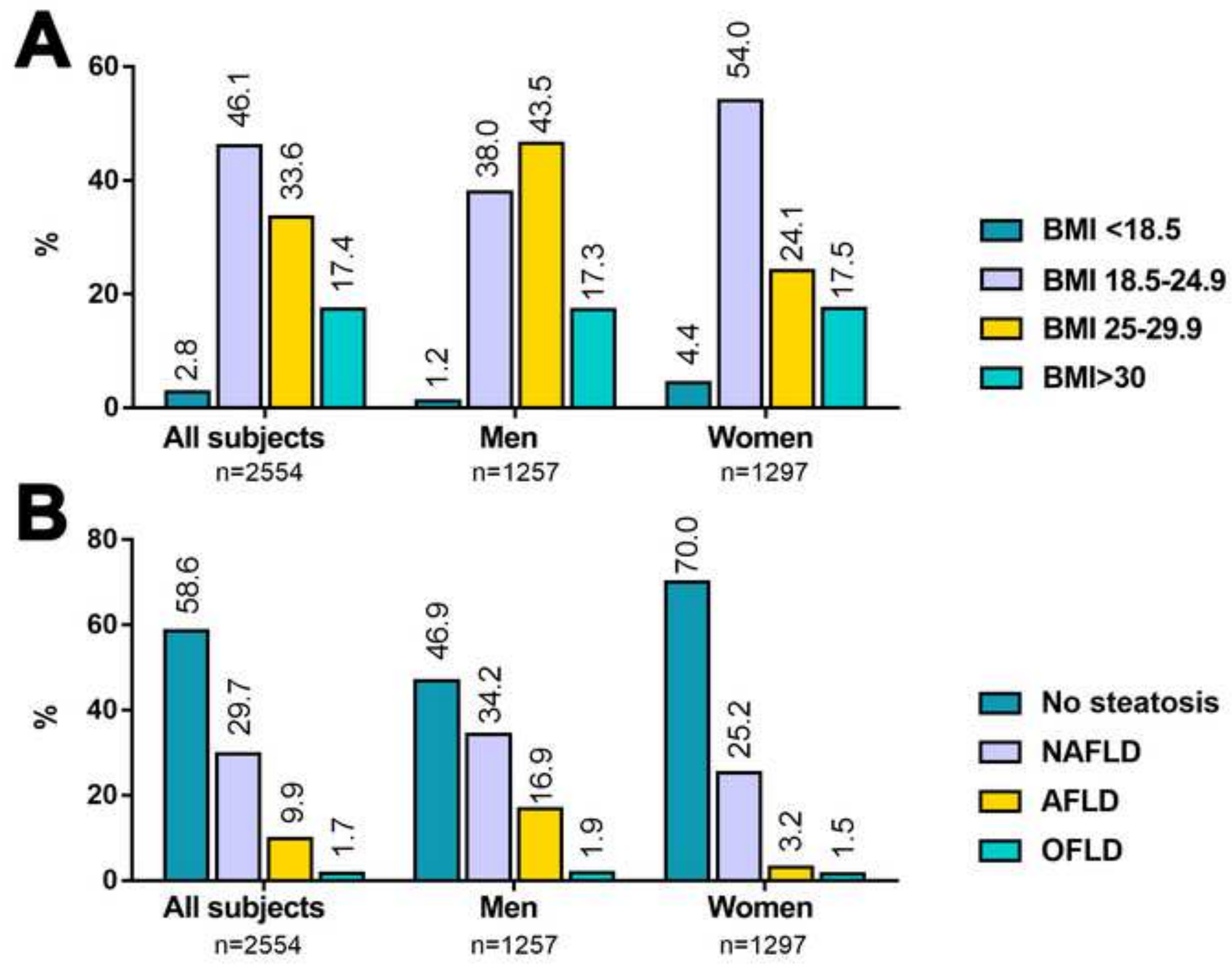



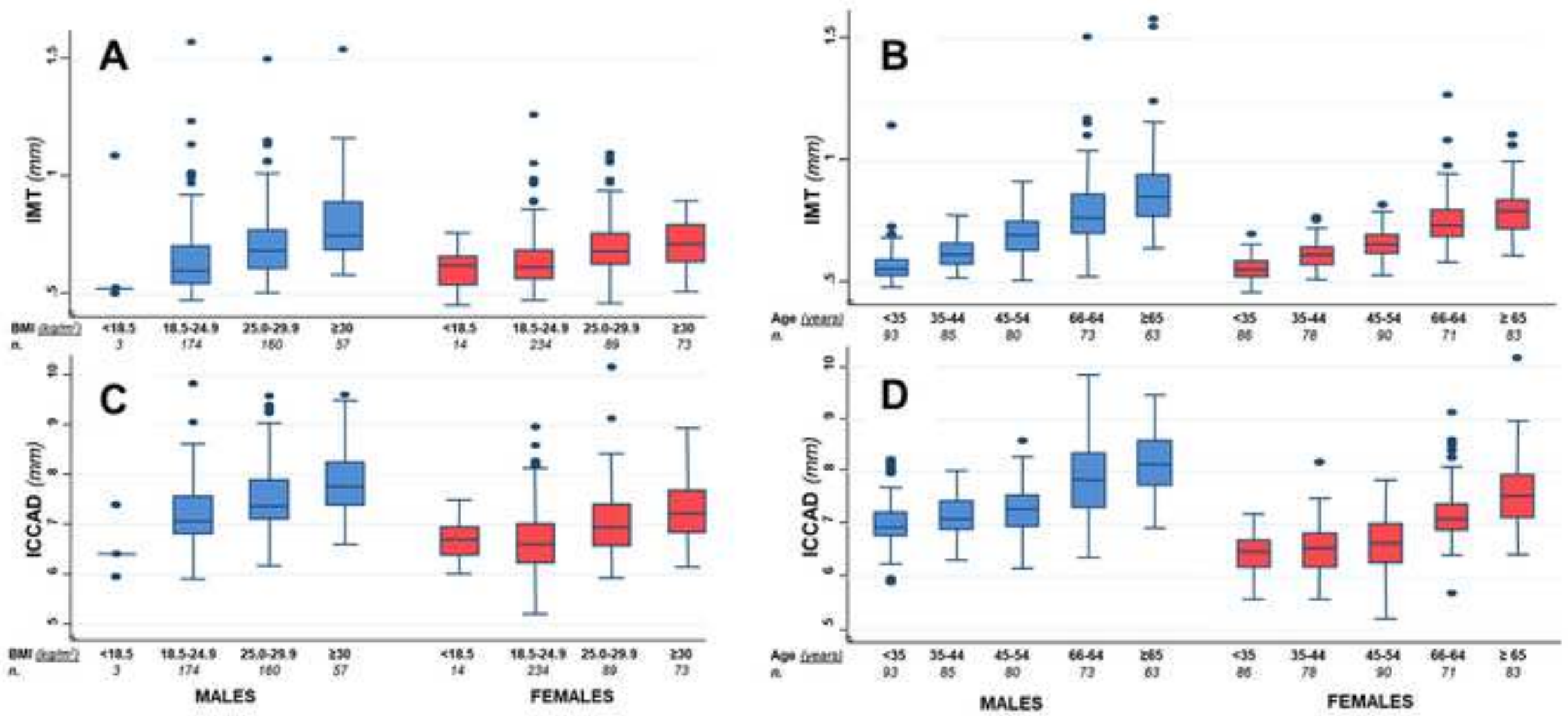


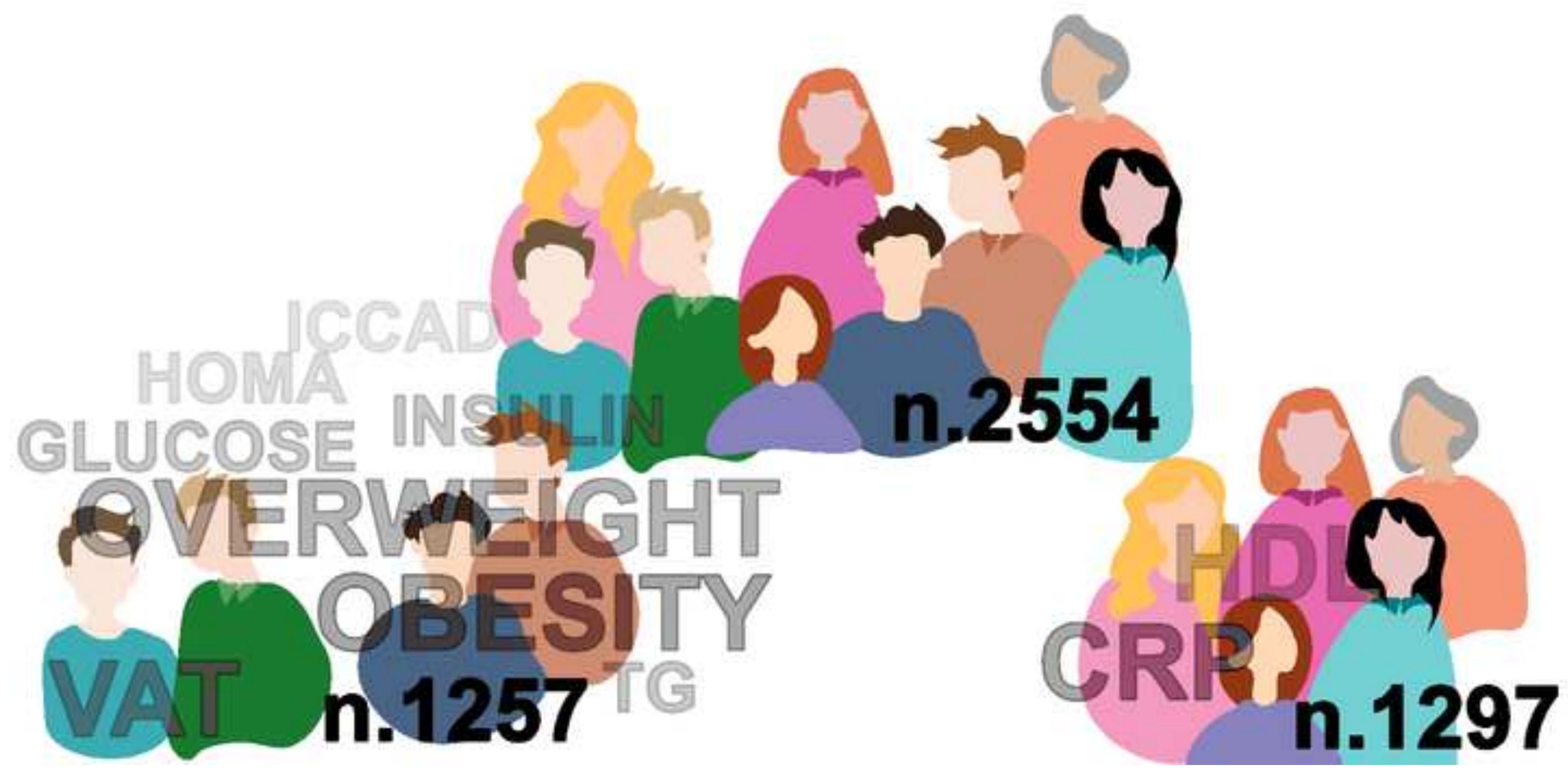




\section{UNIVERSITÀ DEGLI STUDI DI MILANO}

\section{DIPARTIMENTO DI}

SCIENZE DELLA SALUTE

Milan, 29/01/2021

Giovanni Targher, MD, PhD

Professor of Endocrinology and Diabetology

University of Verona, Dpt. of Medicine

Co- Editor

NUTRITION, METABOLISM \& CARDIOVASCULAR DISEASES

\section{RE: manuscript \# NMCD-D-20-01282}

\section{Dear Prof Targher,}

Please find here enclosed the revised version of the manuscript "CA.ME.LI.A. An epidemiological study on the prevalence of cardiovascular, metabolic, liver and autoimmune diseases in Northern Italy Nutrition, Metabolism and Cardiovascular Diseases" ref. NMCD-D-20-01282.

We would like to express our gratitude to you and the reviewer for the extremely helpful comments and for your guidance in the revision. We think that we have addressed all concerns of the reviewer, and we believe that you will appreciate the changes that we have made in response to the comments.

Moreover, as you kindly suggested, we reformatted the highlights with no more than 85 characters and each authors signed the ICMJE Conflict of Interest form.

Now, we hope that our revised manuscript could be accepted for publication in Nutrition, Metabolism and Cardiovascular Diseases.

Thank you again for consideration of our revised manuscript and I look forward to hearing from you at your earliest convenience.

Sincerely yours,

Prof. Franco Folli

Professor in Endocrinology and Metabolism

Department of Health Sciences

Universita' degli Studi di Milano

Via A. Di Rudini' 8

20142 Milano

Italia 
CA.ME.LI.A. An epidemiological study on the prevalence of cardiovascular, metabolic, liver and autoimmune diseases in Northern Italy

Monica Bignotto ${ }^{\mathrm{a}^{*}}$, Michele Dei Cas ${ }^{\mathrm{b}^{*}}$, Rita Paroni ${ }^{\mathrm{b}}$, Elena Bianco ${ }^{\mathrm{a}}$, Paola Zermiani ${ }^{\mathrm{a}}$, Maria Grazia Gangale ${ }^{\mathrm{c}}$, Valentina Zadro ${ }^{a}$, Margherita Maregattia ${ }^{a}$, Alessandra Piagnani ${ }^{a}$, Antonio Russo ${ }^{d}$, Damiano Baldassarre ${ }^{e, f}$,

a Liver and gastroenterology Unit, Department of Health Sciences, Universita' degli Studi di Milano, Milan, Italy

b Clinical Biochemistry and Mass Spectrometry, Department of Health Sciences, Universita' degli Studi di Milano, Milan, Italy

${ }^{c}$ ASST Ovest Milanese, via Papa Giovanni Paolo II, Legnano, Milan, Italy

dEpidemiology Unit, Agency for Health Protection of Milan, Corso Italia 19, 20122, Milan, Italy

e Department of Medical Biotechnology and Translational Medicine, Università degli Studi di Milano, Milan, Italy

f Centro Cardiologico Monzino, IRCCS, Milan, Italy

g Endocrinology and Metabolism, Department of Health Sciences, Universita' degli Studi di Milano, Milan, Italy

${ }^{\text {h }}$ ASST Santi Paolo e Carlo, University Hospital San Paolo, via A. Di Rudini', Milan, Italy

${ }^{*} \mathrm{MB}$ and $\mathrm{MDC}$ equally contributed to the paper

Corresponding authors: Massimo Zuin, Internal Medicine and Liver Unit (massimo.zuin@unimi.it) and Franco Folli (franco.folli@unimi.it) Endocrinology and Metabolism Dipartimento di Scienze della Salute, Universita' degli Studi di Milano, via A. di Rudinì,8, 20142, Milan, Italy. Tel. +39 0250323192

Keywords: Study population; Diabetes; Cardiovascular risk; Metabolic Syndrome; Obesity; Liver disease; epidemiology

Abbreviations: fatty liver disease, FLD; non-alcoholic liver disease, NAFLD; alcoholic steatosis, AFLD; steatosis due to other causes, OFLD; C-reactive protein, CRP; thyroid-stimulating hormone, homocysteine, hCys; TSH; carotid intima-media thickness, C-IMT; confidence intervals, Cl; Body mass index, BMI; underweight, UW; normal weight, NW; overweight, OW; Obese, O; interadventitia common carotid artery diameter, ICCAD; 
Background and Aims. CA.ME.LI.A (CArdiovascular risks, MEtabolic syndrome, Llver and Autoimmune disease) is a cross-sectional, epidemiological study performed 2009-2011 Abbiategrasso (Milan, Italy) to estimate the prevalence of cardiovascular risk factors, metabolic syndrome, liver and autoimmune diseases in the general adult population. This report focuses on the description and presentation of baseline characteristics of the population. Methods and Results. Citizens were randomly selected from the city electoral registers $(n=30903)$, yielding a sample of 2554 subjects ( $M=1257, F=1297$; age, 47 $\pm 15 \mathrm{yrs}$; range 18-77 yrs). Men had higher prevalence of overweight or obesity $(60.8 \%$ vs $41.6 \% ; \mathrm{p}<0.0001)$ and greater thickness of visceral adipose tissue $(40 \pm 19$ vs $27 \pm 17 \mathrm{~mm}$; $p<0.0001$ ); no gender difference was found in subcutaneous adipose tissue thickness. Men also showed higher levels of serum triglycerides, $\gamma$-GT, fasting blood glucose, insulin and Homa-IR Index, while HDL, CRP, and prevalence of elevated ( $>5.0 \mathrm{mg} / \mathrm{L}$ ) CRP were lower. Compared to normal weight men, risk-ratio (RR) of CRP elevation was 1.32 (ns) in overweight and $2.68(p<0.0001)$ in obese subjects. The corresponding figures in females were $2.68(p<0.0001)$ and $5.18(p<0.0001)$. Metabolic syndrome was more frequent in men $(32.7 \%$ vs. $14.5 \%$; RR: $2.24, p<0.0001)$. Interadventitia common carotid artery diameter was higher in men and increased with age and BMI. Conclusions. The present study reports on the overall characteristics of a large population from Northern Italy. It aims to identify the associations among cardiovascular risk factors to prevent their development and progression, improve healthy lifestyle and identify subjects liable to pharmacological interventions. 
Over the last six decades, the study of cardiovascular epidemiology has improved our understanding of the pathogenesis of cardiovascular diseases with the identification of several major risks and the development of strategies for their prevention and treatment [1]. While Framingham Heart Study remains the most popular one, many other studies followed in the United States [2], North and South Europe [3,4], Asia [5], Middle East [6], Latin America [7] and Italy [8-10]. Some Italian population studies estimated the prevalence of diabetes in specific areas of Northern Italian regions [11-13], or the correlation between glucose tolerance and non-alcoholic liver disease (NAFLD) [14]. Another one investigated the correlation between liver enymes and metabolic syndrome [15]. CA.ME.LI.A (CArdiovascular risk, MEtabolic syndrome, Llver disease, Autoimmunity) is a population study specifically designed to identify a cohort representative of a Northern Italy population the metabolic and clinical risk factors for cardiovascular and liver diseases. This paper describes the study design and presents the baseline characteristics of the study population.

\section{METHODS}

\subsection{Description of the CA.ME.LI.A Study}

CA.ME.LI.A is an epidemiological study that took place between 2009 and 2011. It was carried out under the patronage of the Municipality of Abbiategrasso, and the financial support of Istituto Superiore di Sanità, Rome, Italy, and Regione Lombardia. Its main goal was to investigate the associations between cardiovascular, metabolic, hepatobiliary, and autoimmune diseases in a relatively large sample population. This population was specifically selected to be representative of Northern Italy based on economic, social, and cultural characteristics. The cohort consisted of adult inhabitants (age 18-77 years) chosen in the Municipality of Abbiategrasso (MI, Lombardy region), a medium-sized town that on December 31, 2006 counted 30120 residents. The characteristic of this community is an economy based predominantly on agriculture, manufacturing, and service. Our choice fell on the basis of the relative demographic stability of the town, as assessed through the migration flows (immigration rate about $14 \%$ ) in the previous decade.

The CA.ME.LI.A project consisted of two phases: a cross-sectional study (CA.ME.LI.A 1) and a longitudinal study (CA.ME.LI.A 2). CA.ME.LI.A 1 lasted about 28 months (from May 5 th 2009 to September $30^{\text {th }}$, 2011) after an information campaign for the population, with a $1^{\text {st }}$ level survey, followed by a $2^{\text {nd }}$ level survey when clinically indicated. "CA.ME.LI.A 1 comprises four different sections aimed at different objectives. Supplementary Table S1 describes in details the sections of the project and the related investigations, and they were: (1) the cardiovascular (CV) risk factors caused by inflammatory, autoimmune and metabolic factors; (2) the sleep disorders correlated with CV risk; (3) presence of liver diseases and association with metabolic risk factors and (4) the establishment of a biobank to store the serum and plasma samples of people recruited to allow future researches on elements of emerging relevance in the longitudinal phase of the study.

The CA.ME.LI.A 2 study aims to obtain follow-up data on the patients enrolled in CA.ME.LI.A 1 cross-sectional study. All the general practitioners of Abbiategrasso were preliminarily informed of the nature of the CA.ME.LI.A studies during specific meetings. They agreed to provide information concerning all cardiovascular, autoimmune, and neoplastic events in the subjects enrolled during CA.ME.LI.A 1. 
We also took advantage of the administrative database of the inpatient population in Lombardia that includes information on all patients discharged from any hospital in the region: sex, date of birth, discharge diagnoses based on the WHO International Classification of Diseases 9th Edition, Clinical Modification (ICD-9-CM, Supplementary Table S2), dates of hospitalization and discharge, date and cause of death of participants who died in hospital.

Italian citizens enjoy universal income tax-financed healthcare, enabling access to diagnostic and therapeutic procedures in public hospitals after the charge of a small co-payment, both in public hospitals and in those operating within the national or regional healthcare service. Subjects affected by chronic conditions, including CV diseases, can obtain a disease-specific exemption code that frees them from any co-payment. Thus, the number of affected patients who did not request the exemption code was almost nil. Therefore, we used the exemption code to supplement the inpatient registry since it allowed the identification of patients with a specific disease, which never required hospitalization.

Finally, data tracking the vital status of residents are continuously updated by the Central Registry Office of the Lombardia Region: for the purposes of the CA.ME.LI.A 2 study, such data were obtained relatively to the period between enrollment of each subject (May $5^{\text {th }}, 2009$ - September $30^{\text {th }}, 2011$ ) and the date of study termination, i.e., after ten years from the enrollment of the last patient August 31st, 2017. Results of the CA.ME.LI.A 2 study will be the object of a separate report. The details on the location and the staff involved in the study are provided in Supplementary Materials.

\subsection{Organizational Planning and Subjects}

An information campaign aimed at the local population was carried out in the three months preceding the beginning of the project. Epidemiologists of the Italian Istituto Superiore di Sanità, made the enrolment based on the electoral lists and convocation of patients in Abbiategrasso. At the time of enrollment, the number of residents in the Municipality of Abbiategrasso was 30903 (data on December 31, 2006), and 20731 were aged 18-77 years. According to a stratified randomization procedure, one out of six was randomly selected according to age (5-year classes) and sex. They were contacted through two letters delivered at home (30 and 7 days before the convocation). Each letter reported the aims of the study and the day of convocation. The selected subjects were asked to attend in fasting conditions, without smoking or taking coffee in the previous hours, and were asked to bring a list of the medications in use with them. This way, 3650 inhabitants aged 18-77 were selected, and 2554 (1257 men and 1297 women) gave written informed consent to participate in the study and underwent first level exams (Figure S1). Both healthy subjects and patients suffering from diseases such as diabetes, hypertension, and metabolic syndrome were enrolled. Patients with liver disease at the time of recruitment or subjects receiving a diagnosis of alcoholic steatosis during first level investigations were excluded from the CA.ME.LI.A 2, longitudinal study. Recruitment took place between May 2009 and September 2011. Among those who agreed to participate in the study, about 50 subjects per week were contacted for the medical examination. The follow-up period, which ended in August 2017, had a median duration of 7.4 years. The maximum duration of follow-up and total follow-up were 8.3 years and 15568 person-years, respectively. During the follow-up, 32 people (1.25\%) were lost. 


\subsection{Medical Examination}

\subsubsection{First level screening exams}

A food questionnaire (about 90 questions on the subject's eating habits) and a general questionnaire (240 questions regarding social status, work activity, known diseases, and family history, risk factors for cardiovascular and metabolic diseases, physical activity, sleep disorders, physiological history, pharmacological history, description of frequency, type and quantity of alcoholic beverages eventually taken, number of cigarettes smoked) were administered.

After this first phase, subjects moved on to undergo the following investigations (details in Supplementary materials):

1. abdomen ultrasound scan for (1) evaluating the presence of hepatic steatosis, or any areas of focal steatosis; (2) measurement of the transverse diameter of the aorta in the supra and sub-renal area along with hepatic and portal veins; (3) measurement of visceral abdominal fat thickness; (4) measurement of the subcutaneous and antero-peritoneal fat thickness in the sub-xiphoid and supra-umbilical area [16];

2. measurement of arterial blood pressure and anthropometric characteristics;

3. blood tests: complete blood count with leukocyte formula, liver and kidney function, glycaemic and lipid profile, insulinemia, C-reactive protein (CRP, not evaluated by the high-sensitivity assay), homocysteine, iron metabolism, urate, thyroid-stimulating hormone (TSH), anti-HB core, and anti-HCV antibodies. In the case of positive results to the last two examinations, the viral load and genotype in the case of HCV and the complete antibody and antigenic profile in the case of HBV were automatically determined, as well as the search for HDV-Ab and the amount of HBV-DNA.

4. at the same time, after acquiring the informed consent, an aliquot of whole blood was drawn and kept at $-80^{\circ} \mathrm{C}$ with additional aliquots of serum and plasma;

5. carotid arteries B-mode ultrasonography (on $1 / 3$ subjects by randomization);

6. complete urine test (on $1 / 3$ of subjects by randomization).

Laboratory analyses were performed within one hour of blood collection, in the same location. The reading and analysis of carotid intima-media thickness (C-IMT) data were performed in the Doppler echocardiography Unit of the Monzino Cardiology Center in Milan (Prof. D. Baldassarre, see Supplementary materials) [17]. The communication of the first level survey results was sent to the respective general practitioners. In the presence of any clinical or laboratory alteration, even if unrelated to the study, an explanation letter was attached to the investigation results.

\subsubsection{Second level screening}

The second level medical examinations were conducted on all individuals who, in the first phase of the study (screening phase), reported clinical, instrumental, and hematochemical features requiring further investigations. According to National and International Guidelines, communications and subsequent diagnostic-therapeutic procedures were provided to these subjects by their general practitioners. To this purpose, the hospital of Abbiategrasso was made available to carry out the investigations at the Hepatology/Internal Medicine Day Hospital facilities. The results of second level medical tests were also sent to the general practitioners with a cover letter. The 
new diagnostic classification of the participants was recorded in the database of the CA.ME.LI.A Project, which could be available for the follow-up phase of the study.

\subsection{Statistical Analysis}

The results obtained in the present study originated from a database devised explicitly for the CA.ME.LI.A project. Such data were subsequently exported to the Stata statistical analysis software (version 13.0. The STATA Corporation, College Station, Tx. USA). The first clinical events occurring from the date of enrollment to August 2017 and requiring hospitalization were recorded in the computer system of District Milan 1 based on the coding of Hospital Discharge Records (Scheda di Dimissione Ospedaliera, SDO). The compilation and categorization of the SDOs took place based on the ICD-9-CM codes listed in Supplementary Table S2. In addition, mortality data were obtained from the Central Registry Office of the Lombardia region. The data concerning clinical events were obtained by one of the Authors, AR, Head of the Epidemiology Unit, Agency for Health Protection of Milan.

Data were expressed as raw numbers and percentages, prevalence ratios, and $95 \%$ confidence intervals. Continuous variables were presented as mean $\pm S D$, median and range. Differences were assessed using the Mann-Whitney test to compare two groups, or Kruskal-Wallis test, to compare more than two groups. Significant results $(p<0.05)$ from multi-group comparisons were further investigated using Mann-Whitney tests to assess which group differed from the others. For each comparison, the significance value was multiplied by the number of comparisons made (Bonferroni inequality method). Differences in proportions were tested using Fisher's exact test or chi-square statistics. Prevalence rate ratios and their $95 \%$ confidence intervals $(\mathrm{Cl})$ were used to describe the prevalence of a specific finding relative to a reference category.

To estimate risk ratios $(\mathrm{RR})$ or prevalence ratios and simultaneously adjust for the effect of other variables under study, relative risk regression analyses were carried out using a Poisson working model with a robust error variance.

For the analysis of CA.ME.LI.A 2 study data, cumulative proportions of subjects developing a cardiovascular event will be estimated through the Kaplan-Meier approach using the date of enrollment in the CA.ME.LI.A study as the starting point. The final observation time will be considered the first event occurring among the following: a) the first cardiovascular event, $b$ ) the date of death due to cardiovascular causes, $c$ ) the loss of the subject to follow-up, or $d$ ) the date of study termination, i.e. 10 years after enrollment of the last patient, for subjects who will complete the entire follow up period. The log-rank test will be used to assess differences in the incidence of events among groups of subjects. To compare subjects among levels of a continuous variable, they will be typically categorized into quartiles. In any case, the association with cardiovascular events will also be carried out by univariate analysis, introducing it as a continuous variable in Cox time-dependent models. The variables significantly associated by either the log-rank test (categorical variables) or a time-dependent Cox model with a single variable (continuous variables) will be introduced in a multivariate Cox time-dependent model to identify those having an independent prognostic value.

The study protocol established that the analyses should be carried out separately in men and women, given the multiple associations between the studied variables and genders.

When prospectively planning the study, it was assumed an incidence of cardiovascular events, or death, equal to $10 \%$ after seven years from enrollment. It was calculated that at least 1189 subjects in each group would be necessary. This would give a power of at least $90 \%$ to detect a $5 \%$ difference in the incidence of events between two groups 
178 using the two-sided log-rank test [18]. All analyses were two-sided. Differences with $p<0.05$ were considered

179 statistically significant. 


\section{RESULTS}

Of the 2554 participating subjects, 1257 (49.2\%) were men, and 1297(51.8\%) were women. Their age and sex distribution did not differ from that of the general population of Abbiategrasso. The anthropometric characteristics of the study population are reported in Table 1. Except for age and IMTmean, substantial gender differences were observed in the distribution of most variables considered.

According to the WHO classification, subjects were classified as underweight (UW), BMl $<18.5 \mathrm{~kg} / \mathrm{m}^{2}$; normal weight (NW), $18.5-24.9 \mathrm{~kg} / \mathrm{m}^{2}$; overweight (OW), $25-29.9 \mathrm{~kg} / \mathrm{m}^{2}$; obese (O), $\geq 30 \mathrm{~kg} / \mathrm{m}^{2}$. The prevalence of $\mathrm{OW}$ or $\mathrm{O}$ subjects was $60.9 \%$ among men and $41.6 \%$ among women $(\mathrm{p}<0.0001)$ (Figure $\mathbf{1 A}$ and Supplementary Table S3). Visceral Adipose Tissue (VAT) and Subcutaneous Adipose Tissue (SAT) thickness were greater in men than in women $(p<0.0001$, Table 1).

According to the study protocol, ultrasound (US) measurements of the carotid artery intima-media thickness (C-IMT) and interadventitia common carotid artery diameter (ICCAD) were performed as non-invasive indicators of subclinical atherosclerosis in 1:3 subjects were selected according to a random assignment procedure. Results are reported in Table 1. Figure 2 shows the values of the two measurements in the male and female populations stratified according to BMI (Figure 2 panel A,C) or age classes (Figure 2 panel B,D). As expected, both IMT measures were significantly higher in men than in women $(p<0.0001)$. In men, ICCAD showed a progressive increase with age $(+16 \%$ difference between subjects younger than 34 and those older than 65 years) and BMI (+22\% difference between subjects with $\mathrm{BMI}<18.5$ and those with $\mathrm{BMI}>30$ ). Milder increases were found in women (Supplementary Table S4 and S5, Figure 2).

Table 2 reports the baseline biochemical and haematological characteristics. Men showed higher values of serum triglycerides and Gamma-GT (both $\mathrm{p}<0.0001)$. Serum liver enzyme levels, except alkaline phosphatase (ALP), were higher in men than in women as were fasting blood glucose, total homocysteine (hCys), insulin levels and Homa-IR Index. Conversely, total cholesterol, HDL cholesterol, and C-reactive protein (CRP) levels (all $p<0.0001)$ were higher in women.

Elevated ( $>5.0 \mathrm{mg} / \mathrm{L}$ ) CRP values were found in $11.4 \%$ of the overall population, with a higher prevalence in women (13.5\% vs $9.3 \%, p=0.001)$. In the male population, the prevalence of abnormal CRP was associated with increased body weight: compared to subjects with $\mathrm{BMl}<25 \mathrm{~kg} / \mathrm{m}^{2}$, the risk ratio (RR) of having an elevated CRP level was 1.32 $(0.86-2.04 ; \mathrm{ns})$ in overweight males and $2.68(1.72-4.17 ; \mathrm{p}<0.0001)$ in obese men. Stronger associations with inflammation markers were found in women, RR being 2.68 (1.86-3.87; $p<0.0001)$ in overweight, and 5.18 (3.71-7.20; $p<0.0001)$ in obese women.

Smoking and drinking habits along with the personal and family health history in the CA.ME.LI.A population, are reported in Table 3. Smokers or former smokers accounted for $49 \%$ of the whole population, and the prevalence of former smokers was significantly higher in men $(p<0.0001)$. About $60 \%$ of the subjects were alcohol consumers, more frequently men ( $75 \%$ vs $43 \%, p<0.0001)$. Among alcohol consumers, $73 \%$ of subjects $(56 \%$ men and $89 \%$ women) drank less than $15 \mathrm{~g}$ of alcohol per day and $27 \%$ (44\% men and $11 \%$ women) drank more than $15 \mathrm{~g} /$ day. About $43 \%$ of the population reported a sedentary lifestyle (Table 3) and 7\% reported a previous diagnosis of diabetes ( $9 \%$ men and $5 \%$ women; $\mathrm{p}<0.0001)$. Cardiovascular disease had been diagnosed in $8 \%$ of the population: the overall prevalence of myocardial infarction was $3 \%$ and was higher among men $(p=0.0006)$. Ischemic stroke had been diagnosed in $1 \%$ of the whole population. The prevalence of hypertension, defined as a systolic blood pressure $\geq 140$ 
$\mathrm{mmHg}$, or diastolic blood pressure $\geq 90 \mathrm{mmHg}$, or anti-hypertensive medication was $23 \%$ in the whole population with no gender difference. Women more frequently reported a family history of cardiovascular diseases and hypertension.

221 Table 4 reports the prevalence of metabolic syndrome and its determinants according to the National Cholesterol Education Program Adult Treatment Panel III criteria [19]. Metabolic syndrome was detected in $23.3 \%$ of the subjects and was more prevalent in men $(32.7 \%$ vs, $14.5 \%$; $p<0.0001)$ with a male to female $R R$ of $2.24(1.92-2.610 ; p<0.001)$. In the 2554 subjects who underwent upper US examination, the detection rate of fatty liver disease (FLD) was $41.3 \%$ (Figure 1B, Supplementary Table S6) and was significantly higher in men (53\% vs. $30 \% ; p<0.0001)$. Among the 1056 subjects with FLD, $71.9 \%$ had non-alcoholic steatosis (NAFLD), $23.9 \%$ alcoholic steatosis (AFLD), while $4.2 \%$ of steatosis was ascribed to other causes, including HBV or HCV infection, hemochromatosis, and Wilson disease 228 (OFLD).

229 Treatment with oral medications was quite limited in the population, with the exception of anti-hypertensive drugs, the use of which was reported by $21.3 \%$ of the population (21\% of men and $22 \%$ of women; ns) (Supplementary Table S7). 


\section{DISCUSSION}

This paper describes the general structure of the CA.ME.LI.A project and gives a metabolic snapshot of the Abbiategrasso population, providing the baseline characteristics and identifying sex differences in the main variables associated with cardiovascular risk and metabolic syndrome. So far, no study has yet presented the general characteristics of the project, even if other sector-specific papers based on the CA.ME.LI.A database have been published [20-22].

This paper presents only the cross-sectional data characterizing the population of the study at the baseline. We do not present longitudinal data because the follow-up is still ongoing with the expectation to reach the 10-years observation period in line with other epidemiological studies [23-25].

Smoking and drinking habits of Abbiategrasso population were very close to those reported by the Italian Istituto Superiore di Sanità in 2011 at national level [26,27]. Interestingly, the number of subjects claiming not to drink at all (teetotalers) in our cohort was about $39 \%$ (prevalently women), while in Italy it was $29.3 \%$ [28].

The prevalence of chronic diseases in Abbiategrasso was in line with the national values: diabetes accounting for $7 \%$ in Abbiategrasso ( $9 \%$ men, $5 \%$ women) vs. $5.3 \%$ in Italy; chronic renal failure was estimated at $8 \%(9 \%$ men, $7 \%$ women) vs. $8.3 \%$ in Italy ( $6.6 \%$ men and $6.3 \%$ women) [29]. About hypertension, data obtained in Abbiategrasso (tot. $23 \%, 24 \%$ men, $22 \%$ women) are slightly different from those in the registry of Italian General Practitioners (GPs). In the latter, the prevalence of hypertension shows a growing trend (from 21.0-26.7\% between 2005-2013) and it is higher in women $(27.4 \%$ in 2013$)$ than in men $(26 \%$ in 2013$)$ [30]. The cardiovascular risk was equal to $24 \%(27 \%$ in men, $22 \%$ in women), while in the whole country it was around $23 \%$. The prevalence of subjects who admitted a sedentary lifestyle among Abbiategrasso residents was relatively higher: $43 \%$ vs. $30 \%$ in Italy [26].

Men, compared to women, displayed higher serum levels of almost all the biochemical indices, except HDL and CRP. In line with the literature [31-33] also in our study women displayed a higher prevalence of altered CRP values ( $\geq 5$ $\mathrm{mg} / \mathrm{L})$ compared to men $(13.5 \%$ vs $9.3 \%, \mathrm{p}<0.0001)$, with a strong association with inflammation. CRP is a useful inflammatory biomarker of incident clinical cardiovascular disease, although there is a debate over its role as a causal factor; for example, in the Dallas Hearth Study on 2749 subjects participating the investigation [32], significant race and gender differences were found in the distribution of CRP. Further analysis on our data will allow not only to confirm the differences observed in the Dallas Study, based both on gender and ethnic difference, but also to evaluate the correlation between CRP and BMI, which appears to be stronger than other continuous variables, including age and all measured lipid risk factors. Prospective studies are recommended to better assess the usefulness of CRP as a marker of atherosclerotic cardiovascular disease and cardiovascular risk predictor in women and particularly in type 2 diabetes [33]. Since the end of the CA.ME.LI.A study many novel biomarkers involved, demonstrating the connection among diabetes, inflammation and cardiovascular diseases, have been proposed and validated [34-39]. Many of these will be possibily included in our future studies on the CA.ME.LI.A cohort.

Another important aspect, which will be the subject of further investigation on the data of the CA.ME.LI.A project, is the role of hyperinsulinemia and insulin resistance. In fact, higher plasma glucose and triglycerides, lower HDL cholesterol, increase in both systolic and diastolic blood pressure are closely linked to augmented risk of coronary heart disease, also in nondiabetic individuals $[40,41]$. 
Regarding BMI data, those reported in the Istat surveys on the Italian population reported a mean BMI of $25 \mathrm{~kg} / \mathrm{m}^{2}$, borderline and overweight $46.5 \%$, while $10.5 \%$ trespass obesity. In Southern Italy, the overweight percentage concerns $60-65 \%$ of the population, and obesity $30 \%$ [42]. "Mediterranean dietary style" [43,44], together with the absence of a systematic increase in portion size [27], may have been important factors that contributed to counteract the epidemic of obesity in Italy, in comparison with United States (about 35\% on the whole population) [46].

The results coming from CA.ME.LI.A are consistent with those mentioned, where the mean BMI in both sexes was borderline $\left(25.8 \mathrm{~kg} / \mathrm{m}^{2}\right)$ with the overall prevalence of overweight and obesity $\left(\geq 25 \mathrm{~kg} / \mathrm{m}^{2}\right)$ of $51 \%, 60.9 \%$ in men and $41.6 \%$ in women ( $p<0.0001$, Figure 1A, and Supplementary Table S3). The percentages regarding Italy for gender differences of overweight and obesity (55.6\% men vs. $36.8 \%$ women) are consistent with the ones detected in Abbiategrasso (ns, $\mathrm{p}=0.56$ ) and shown in Table S3 [47]. Overweight is much more common in men than in women, as well as obesity, although to a lesser degree.

Furthermore, overweight/obesity are heterogeneous conditions, and their definition based on BMI alone is insufficient to explain the variability in the onset of cardiovascular and metabolic clinical diseases [48]. In fact, VAT and SAT were also measured in order to better understand if a different distribution of body fat could be associated with differences in morbidity and mortality. VAT, which is a more pathogenic fat depot and generally associated with increased cardiometabolic risk, was higher in men than in women. On the other hand, no gender differences were found in SAT thickness. VAT thickness is more significantly associated with metabolic and cardiovascular risk factors than BMI and high waist circumference [49].

Interesting data also came from the evaluation of the liver and abdomen ultrasound, which allowed to identify that the $41 \%$ of participants presented a prevalence of FLD, particularly $53 \%$ men and $30 \%$ women, while in Italy FLD prevalence ranges are between $20 \%$ and $30 \%$ [50]. The FLD is generally a manifestation of alcohol consumption but, if present in abstemious subjects (non-alcoholic fatty liver disease; NAFLD), it may constitute an early indicator of the risk of incipient liver diseases and non-hepatic diseases (e.g. diabetes and lipid dysmetabolism, cardiovascular diseases, problems in terms of metabolism) [51-53]. In Abbiategrasso, the FLD was identified in 1/3 of subjects who stated that they were not alcohol users and it was present in $45 \%$ of overweight subjects and in $60-70 \%$ of obese people. FLD, in fact, is commonly associated with visceral obesity, type 2 diabetes mellitus, dyslipidemia, and hypertension, all components of the metabolic syndrome, so that FLD might be considered an additional component of the metabolic syndrome itself [54].

The ICCAD and IMT values, obtained from carotid ultrasound, complete the scenario of the critical variables for cardiovascular risk. Carotid IMT reveals a structural deterioration of the arterial wall, it is considered a significant predictive marker of generalized atherosclerosis and cardiovascular events in adults, and for this reason, it is often used as a risk predictor for cardiovascular complications in epidemiological studies [55]. ICCAD values could add strength to IMT measurements and may improve risk assessment in asymptomatic individuals despite not many studies consider the prognostic value of ICCAD [56].

In the CA.ME.LI.A population, almost all IMT measurements are significantly different between sex (Table 1). Moreover, there is a close-proportionate increase of IMT mean from 18 to $77 \mathrm{yrs}$ (the regular ultrasound aspect of the arterial parade changes: it thickens uniformly, especially in the straight vascular segments) in both sexes (Figure 2B and Table S5). This increase is not synonymous with subclinical atherosclerosis but is related to it [57]. The same considerations apply to the relationship between IMTmean and BMI (Figure 2A, Table S4). 
In our population, ICCAD confirms the information coming from IMT data and shows increased values, about $+15 \%$ from 18 to $77 \mathrm{yrs}$, both in men and in women (Figure 2D, Table S5), even if the most meaningful variable is the relationship with the increase in BMI $\left(18.5-30 \mathrm{~kg} / \mathrm{m}^{2}\right)$ that accounts for $+21.8 \%$ in men and $+7.4 \%$ in women (Figure 2C, Table S4).

ICCAD correlates with age, but it is accelerated by the presence of the same risk factors known for atherosclerotic disease. The examination, in fact, allows us to identify the onset of early atherosclerosis: if this will be found in subjects suffering from steatosis, we will have taken a step forward in demonstrating the connection between the two.

A concrete effect of the CA.ME.LI.A project has emerged in several cases. Indeed, for many subjects enrolled in the study medical tests have highlighted the need for more detailed clinical examinations. This was done by developing a personalized diagnostic path, in agreement with the patient's general practitioner. The second level tests involved $14 \%$ of the citizens who participated in the study, making it possible to identify pathologies that had not previously been diagnosed.

\section{Strengths}

The strengths of the project are multiple: high participation of citizens guarantees an accurate statistical analysis $(71 \%$ of the enrolled), the subjects were recruited through a randomization process that allowed to have a sample that reflected the entire population, homogeneously distributed by gender and age. Both healthy subjects and patients affected by diabetes, hypertension, metabolic syndrome, and others were enrolled. The data collected during the enrollment of the subjects were complete, precise and accurate, and more importantly, consistent with the larger frame because of little relevance of bias within the findings. Finally, it is worth noting that this study recorded a low number of patients lost during the follow-up.

\section{Limitations}

The survival study could be affected by the presence of unregistered alcohol abuse, as it was not possible to determine with certainty what the total intake of alcohol was by the people enrolled. The selected population was purified by all subjects diagnosed with AFLD (alcoholic steatosis) to minimize the possible effect of alcohol abuse on survival estimation,

In $20 \%$ of the registered deaths, it was impossible to trace the cause, so they were categorized as "deaths from another cause". It is possible that the hospital discharge card reported the main disease of the subject, without considering that a possible cardiovascular event may have been contributed to the death. It is also possible that some subjects went through cerebral or cardiovascular events but did not go to the hospital, therefore they were not registered in the database. These represent limits to the study because, this way, the number of deaths or cardiovascular events could be underestimated.

\section{Conclusions}

In conclusion, with the snapshot of Abbiategrasso, we believe we may provide a good picture of Northern Italy, without taking into account the variability in regional habits such as lifestyle and diet. This study should be considered a starting point for prevention programs aimed at the diseases investigated.

Acknowledgments: MDC was supported by the PhD program in Molecular and Translational Medicine by the Università degli Studi di Milano, Milan, Italy. We thank Camillo Morano for the English editing. 
351 Conflict of interest: The authors have nothing to disclose.

353 Funding: The CAMELIA project was supported by Regione Lombardia (DG Sanità 08/07/2008 n. 7364), Italian

354 Ministry for Education (MIUR, GR-2011 02350447) and also by Dipartimento di Scienze della Salute, Università degli 355 Studi di Milano (Fondo Incentivo alla Ricerca_CDD 19/03/2019 Progetto dal titolo "NewbioCOR"). 
[1] Vasan RS, Benjamin EJ. The future of cardiovascular epidemiology. Circulation 2016;133:2626-33.

[2] Berenson GS. Childhood Risk Factors Oredict Adult Risk Bogalusa. Am J Cardiol 2002;90:3-7.

[3] Verschuren WMM, Jacobs DR, Bloemberg BPM, Kromhout D, Menotti A, Aravanis C, et al. Serum Total Cholesterol and Long-term Coronary Heart Disease Mortality in Different Cultures: Twenty-five-Year Followup of the Seven Countries Study. JAMA 1995;274:131-6. https://doi.org/10.1001/jama.1995.03530020049031.

[4] Menotti A, Keys A, Blackburn H, Kromhout D, Karvonen M, Nissinen A, et al. Comparison of multivariate predictive power of major risk factors for coronary heart diseases in different countries: results from eight nations of the Seven Countries Study, 25-year follow-up. J Cardiovasc Risk 1996;3:69-75.

[5] Ueshima H, Sekikawa A, Miura K, Turin TC, Takashima N, Kita Y, et al. Cardiovascular disease and risk factors in Asia: a selected review. Circulation 2008;118:2702-9.

[6] Ahmed AM, Hersi A, Mashhoud W, Arafah MR, Abreu PC, Al Rowaily MA, et al. Cardiovascular risk factors burden in Saudi Arabia: the Africa Middle East cardiovascular epidemiological (ACE) study. J Saudi Hear Assoc 2017;29:235-43.

[7] Jahangir E, Comandé D, Rubinstein A. Cardiovascular disease research in Latin America: a comparative bibliometric analysis. World J Cardiol 2011;3:383.

[8] Olmastroni E, Shlyakhto E V, Konradi AO, Rotar OP, Alieva AS, Boyarinova MA, et al. Epidemiology of cardiovascular risk factors in two population-based studies. Atheroscler Suppl 2018;35:e14-20.

[9] Volpe R, Nati G, Chiriatti A, Sabatini M, Valente F. Hypertriglyceridemia, an Underestimated Cardiovascular Risk Factor: An Epidemiological Study of the Rome Area. High Blood Press Cardiovasc Prev 2017;24:401-4.

[10] Giampaoli S, Palmieri L, Donfrancesco C, Noce C Lo, Pilotto L, Vanuzzo D. Cardiovascular health in Italy. Tenyear surveillance of cardiovascular diseases and risk factors: Osservatorio Epidemiologico Cardiovascolare/Health Examination Survey 1998-2012. Eur J Prev Cardiol 2015;22:9-37.

[11] Muggeo M, Verlato G, Bonora E, Bressan F, Girotto S, Corbellini M, et al. The Verona diabetes study: a population-based survey on known diabetes mellitus prevalence and 5-year all-cause mortality. Diabetologia 1995;38:318-25. https://doi.org/10.1007/BF00400637.

[12] Bonetti S, Trombetta M, Boselli ML, Turrini F, Malerba G, Trabetti E, et al. Variants of GCKR affect both $\beta$-cell and kidney function in patients with newly diagnosed type 2 diabetes: The verona newly diagnosed type 2 diabetes study 2. Diabetes Care 2011;34:1205-10. https://doi.org/10.2337/dc10-2218.

[13] Garancini MP, Sergi A, Lazzari P, Gallus G. Epidemiology of known diabetes in Lombardy, north Italy. Clinical characteristics and methodological aspects 1995:268-72.

[14] Sesti G, Hribal ML, Fiorentino TV, Sciacqua A, Perticone F. Elevated $1 \mathrm{~h}$ postload plasma glucose levels identify adults with normal glucose tolerance but increased risk of non-alcoholic fatty liver disease. BMJ Open Diabetes Res Care 2014;2:e000016. https://doi.org/10.1136/bmjdrc-2014-000016.

[15] Nannipieri M, Gonzales C, Baldi S, Posadas R, Williams K, Haffner SM, et al. Liver enzymes, the metabolic syndrome, and incident diabetes: The Mexico City diabetes study. Diabetes Care 2005;28:1757-62. https://doi.org/10.2337/diacare.28.7.1757.

[16] Mishra P, Younossi ZM. Abdominal ultrasound for diagnosis of nonalcoholic fatty liver disease (NAFLD). Am J Gastroenterol 2007. https://doi.org/10.1111/j.1572-0241.2007.01520.x.

[17] Baldassarre D, Hamsten A, Veglia F, De Faire U, Humphries SE, Smit AJ, et al. Measurements of carotid intima-media thickness and of interadventitia common carotid diameter improve prediction of cardiovascular events: Results of the IMPROVE (carotid intima media thickness [IMT] and IMT-progression as predictors of vascular events in. J Am Coll Cardiol 2012. https://doi.org/10.1016/j.jacc.2012.06.034.

[18] Freedman LS. Tables of the number of patients required in clinical trials using the logrank test. Stat Med 1982;1:121-9.

[19] Third Report of the National Cholesterol Education Program (NCEP) Expert Panel on Detection, Evaluation, and Treatment of High Blood Cholesterol in Adults (Adult Treatment Panel III) final report. Circulation 2002. https://doi.org/10.1097/00019616-199311000-00022.

[20] Selmi C, De Santis M, Battezzati PM, Generali E, Lari SA, Ceribelli A, et al. Anti-phospholipid antibody prevalence and association with subclinical atherosclerosis and atherothrombosis in the general population. Int J Cardiol 2020;300:209-13. https://doi.org/10.1016/j.ijcard.2019.10.042. 
[21] Franzini M, Lorenzoni V, Masotti S, Prontera C, Chiappino D, Latta D Della, et al. The calculation of the cardiac troponin T 99th percentile of the reference population is affected by age, gender, and population selection: A multicenter study in Italy. Clin Chim Acta 2015;438:376-81. https://doi.org/10.1016/j.cca.2014.09.010.

[22] Zuin M, Caserta C, Romanò L, Mele A, Zanetti A, Cannatelli R, et al. Seroepidemiology of HEV and HAV in two populations with different socio-economic levels and hygienic/sanitary conditions. Eur J Clin Microbiol Infect Dis 2017;36:479-85. https://doi.org/10.1007/s10096-016-2821-7.

[23] Calori G, Lattuada G, Ragogna F, Garancini MP, Crosignani P, Villa M, et al. Fatty liver index and mortality: The cremona study in the 15th year of follow-up. Hepatology 2011;54:145-52. https://doi.org/10.1002/hep.24356.

[24] Calori G, Lattuada G, Piemonti L, Garancini MP, Ragogna F, Villa M, et al. Prevalence, Metabolic features, and prognosis of metabolically healthy obese italian individuals: The cremona study. Diabetes Care 2011;34:2105. https://doi.org/10.2337/dc10-0665.

[25] Perseghin G, Calori G, Lattuada G, Ragogna F, Dugnani E, Garancini MP, et al. Insulin resistance/hyperinsulinemia and cancer mortality: The Cremona study at the 15th year of follow-up. Acta Diabetol 2012;49:421-8. https://doi.org/10.1007/s00592-011-0361-2.

[26] ISTAT. Italy in figures 2012. https://www.istat.it/it/files//2011/06//taly2012.pdf.

[27] ISTAT. Archivio comunicati uso e abuso di alcol in Italia 2010. https://www.istat.it/it/files//2011/04/testointegrale20110405.pdf.

[28] Epidemiologia e monitoraggio alcol-correlato in Italia e nelle Regioni Valutazione dell'Osservatorio Nazionale Alcol sull'impatto del consumo di alcol ai fini dell'implementazione delle attività del Piano Nazionale Alcol e Salute Rapporto 2019. https://www.iss.it/documents/20126/45616/19_5_web.pdf/709f13e3-164e-6db9-df5a7dac6702fc7f?t=1581095844426.

[29] Ravaglia F, Francesconi P, Profili F, Rosati A. Prevalence of chronic kidney disease in italy: the role of demographic shift towards older age groups. Nephrol Dial Transplant 2018;33:150-1. https://doi.org/10.1093/ndt/gfy104.

[30] Health Search Registry of the Italian GPs 2014 2014. www.healthsearch.it.

[31] Lakoski SG, Cushman M, Criqui M, Rundek T, Blumenthal RS, D'Agostino RB, et al. Gender and C-reactive protein: Data from the Multiethnic Study of Atherosclerosis (MESA) cohort. Am Heart J 2006. https://doi.org/10.1016/j.ahj.2006.02.015.

[32] Khera A, McGuire DK, Murphy SA, Stanek HG, Das SR, Vongpatanasin W, et al. Race and gender differences in C-reactive protein levels. J Am Coll Cardiol 2005. https://doi.org/10.1016/j.jacc.2005.04.051.

[33] Qasim AN, Budharaju V, Mehta NN, St Clair C, Farouk S, Braunstein S, et al. Gender differences in the association of C-reactive protein with coronary artery calcium in Type-2 diabetes. Clin Endocrinol (Oxf) 2011. https://doi.org/10.1111/j.1365-2265.2010.03879.x.

[34] Casagrande V, Menghini R, Menini S, Marino A, Marchetti V, Cavalera M, et al. Overexpression of tissue inhibitor of metalloproteinase 3 in macrophages reduces atherosclerosis in low-density lipoprotein receptor knockout mice. Arterioscler Thromb Vasc Biol 2012;32:74-81. https://doi.org/10.1161/ATVBAHA.111.238402.

[35] Federici M, Hribal ML, Menghini R, Kanno H, Marchetti V, Porzio O, et al. Timp3 deficiency in insulin receptor Haploinsufficient mice promotes diabetes and vascular inflammation via increased TNF- $\alpha$. J Clin Invest 2005;115:3494-505. https://doi.org/10.1172/JCl26052.

[36] Menghini R, Fiorentino L, Casagrande V, Lauro R, Federici M. The role of ADAM17 in metabolic inflammation. Atherosclerosis 2013;228:12-7. https://doi.org/10.1016/j.atherosclerosis.2013.01.024.

[37] Tripathy D, Daniele G, Fiorentino T V., Perez-Cadena Z, Chavez-Velasquez A, Kamath S, et al. Pioglitazone improves glucose metabolism and modulates skeletal muscle TIMP-3-TACE dyad in type 2 diabetes mellitus: A randomised, double-blind, placebo-controlled, mechanistic study. Diabetologia 2013;56:2153-63. https://doi.org/10.1007/s00125-013-2976-z.

[38] Fiorentino TV, Monroy A, Kamath S, Sotero R, Cas MD, Daniele G, et al. Pioglitazone corrects dysregulation of skeletal muscle mitochondrial proteins involved in ATP synthesis in type 2 diabetes. Metabolism 2020;0:154416. https://doi.org/10.1016/j.metabol.2020.154416.

[39] Monroy A, Kamath S, Chavez AO, Centonze VE, Veerasamy M, Barrentine A, et al. Impaired regulation of the TNF- $\alpha$ converting enzyme/tissue inhibitor of metalloproteinase 3 proteolytic system in skeletal muscle of obese type 2 diabetic patients: A new mechanism of insulin resistance in humans. Diabetologia 2009;52:2169-81. https://doi.org/10.1007/s00125-009-1451-3. 
[40] Zavaroni I, Bonora E, Pagliara M, Dall'aglio E, Luchetti L, Buonanno G, et al. Risk Factors for Coronary Artery Disease in Healthy Persons with Hyperinsulinemia and Normal Glucose Tolerance. N Engl J Med 1989;320:702-6. https://doi.org/10.1056/NEJM198903163201105.

[41] Zavaroni I, Bonini L, Gasparini P, Barilli AL, Zuccarelli A, Dall'Aglio E, et al. Hyperinsulinemia in a normal population as a predictor of non-insulin- dependent diabetes mellitus, hypertension, and coronary heart disease: The Barilla Factory revisited. Metabolism 1999;48:989-94. https://doi.org/10.1016/S00260495(99)90195-6.

[42] ISTAT. Italy in figures 2016. https://www.istat.it/it/files//2017/06/Italy_in_figures_16.pdf.

[43] Trichopoulou A, Naska A, Orfanos P, Trichopoulos D. Mediterranean diet in relation to body mass index and waist-to-hip ratio: The Greek European Prospective Investigation into Cancer and Nutrition Study. Am J Clin Nutr 2005. https://doi.org/10.1093/ajcn/82.5.935.

[44] Paroni R, Dei Cas M, Rizzo J, Ghidoni R, Montagna MT, Rubino FM, et al. Bioactive phytochemicals of tree nuts. Determination of the melatonin and sphingolipid content in almonds and pistachios. J Food Compos Anal 2019;82:103227. https://doi.org/10.1016/j.jfca.2019.05.010.

[45] Silventoinen K, Sans S, Tolonen H, Monterde D, Kuulasmaa K, Kesteloot H, et al. Trends in obesity and energy supply in the WHO MONICA Project. Int J Obes 2004. https://doi.org/10.1038/sj.ijo.0802614.

[46] Fryar CD, Carroll MD, Ogden CL. Prevalence of Overweight, Obesity, and Extreme Obesity Among Adults Aged 20 and Over: United States, 1960-1962 Through 2013-2014. Heal E-Stats 2016:1-6.

[47] Eurostat. Overweight and obesity - BMI statistics 2014. https://ec.europa.eu/eurostat/statisticsexplained/index.php/Overweight_and_obesity_-_BMI_statistics.

[48] Ertunc ME, Hotamisligil GS. Lipid signaling and lipotoxicity in metaflammation: Indications for metabolic disease pathogenesis and treatment. J Lipid Res 2016;57:2099-114. https://doi.org/10.1194/jlr.R066514.

[49] Gruzdeva O, Borodkina D, Uchasova E, Dyleva Y, Barbarash O. Localization of fat depots and cardiovascular risk. Lipids Health Dis 2018;17:218. https://doi.org/10.1186/s12944-018-0856-8.

[50] Lonardo A, Nascimbeni F, Targher G, Bernardi M, Bonino F, Bugianesi E, et al. AISF position paper on nonalcoholic fatty liver disease (NAFLD): Updates and future directions. Dig Liver Dis 2017;49:471-83. https://doi.org/10.1016/j.dld.2017.01.147.

[51] Eslam M, Newsome PN, Sarin SK, Anstee QM, Targher G, Romero-Gomez M, et al. A new definition for metabolic dysfunction-associated fatty liver disease: An international expert consensus statement. J Hepatol 2020;73:202-9. https://doi.org/10.1016/j.jhep.2020.03.039.

[52] Lonardo A, Nascimbeni F, Mantovani A, Targher G. Hypertension, diabetes, atherosclerosis and NASH: Cause or consequence? J Hepatol 2018;68:335-52. https://doi.org/10.1016/j.jhep.2017.09.021.

[53] Bifari F, Manfrini R, Dei Cas M, Berra C, Siano M, Zuin M, et al. Multiple target tissue effects of GLP-1 analogues on non-alcoholic fatty liver disease (NAFLD) and non-alcoholic steatohepatitis (NASH). Pharmacol Res 2018;137:219-29. https://doi.org/10.1016/j.phrs.2018.09.025.

[54] Loria P, Adinolfi LE, Bellentani S, Bugianesi E, Grieco A, Fargion S, et al. Practice guidelines for the diagnosis and management of nonalcoholic fatty liver disease. A decalogue from the Italian Association for the Study of the Liver (AISF) Expert Committee. Dig Liver Dis 2010;42:272-82. https://doi.org/10.1016/j.dld.2010.01.021.

[55] Sillesen H. Carotid intima-media thickness and/or carotid plaque: What is relevant? Eur J Vasc Endovasc Surg 2014;48:115-7. https://doi.org/10.1016/j.ejvs.2014.04.026.

[56] Nambi V, Chambless L, Folsom AR, He M, Hu Y, Mosley T, et al. Carotid Intima-Media Thickness and Presence or Absence of Plaque Improves Prediction of Coronary Heart Disease Risk. The ARIC (Atherosclerosis Risk In Communities) Study. J Am Coll Cardiol 2010;55:1600-7. https://doi.org/10.1016/j.jacc.2009.11.075.

[57] Simova I. Intima-media thickness: Appropriate evaluation and proper measurement, described. Eur Soc Cardiol 2015;13:1-14. 
Tables.

Table 1. Baseline anthropometric and ultrasonographic characteristics in the CA.ME.LI.A study population

\begin{tabular}{|c|c|c|c|c|c|c|c|c|c|c|}
\hline & \multicolumn{3}{|c|}{ All subjects $(n=2554)$} & \multicolumn{3}{|c|}{ Men $(n=1257)$} & \multicolumn{3}{|c|}{ Women $(n=1297)$} & \multirow[b]{2}{*}{$p$} \\
\hline & $\begin{array}{l}\text { Mean } \\
\pm S D\end{array}$ & Median & $\begin{array}{l}\text { Range } \\
(\min - \\
\max ) \\
\end{array}$ & $\begin{array}{c}\text { Mean } \\
\pm S D\end{array}$ & Median & $\begin{array}{l}\text { Range } \\
(\min - \\
\max )\end{array}$ & $\begin{array}{l}\text { Mean } \\
\pm S D\end{array}$ & Median & $\begin{array}{l}\text { Range } \\
(\min - \\
\max )\end{array}$ & \\
\hline Age (years) & $47 \pm 15$ & 47.0 & $18-77$ & $47 \pm 15$ & 46 & $19-77$ & $48 \pm 15$ & 47 & $18-77$ & ns \\
\hline Weight (Kg) & $72 \pm 16$ & 71 & $37-142$ & $80 \pm 13$ & 78 & $42-142$ & $64 \pm 14$ & 61 & $37-130$ & $<0.0001$ \\
\hline Height $(\mathrm{cm})$ & $167 \pm 10$ & 167 & 134-198 & $174 \pm 7$ & 174 & $151-198$ & $160 \pm 7$ & 160 & $134-182$ & $<0.0001$ \\
\hline BMI $\left(\mathrm{kg} / \mathrm{m}^{2}\right)$ & $25.8 \pm 5$ & 25 & $16-53$ & $26 \pm 4$ & 26 & $16-45$ & $25 \pm 6$ & 24 & $16-53$ & $<0.0001$ \\
\hline $\begin{array}{l}\text { Waist } \\
\text { circumference } \\
(\mathrm{cm})\end{array}$ & $92 \pm 13$ & 91 & $43-174$ & $95 \pm 12$ & 95 & $43-174$ & $88 \pm 13$ & 86 & $60-150$ & $<0.0001$ \\
\hline SBP $(\mathrm{mmHg})$ & $123 \pm 18$ & 120 & $80-230$ & $125 \pm 17$ & 122 & $87-210$ & $120 \pm 19$ & 117 & $80-230$ & $<0.0001$ \\
\hline DBP $(\mathrm{mmHg})$ & $77 \pm 11$ & 78 & $48-130$ & $79 \pm 10$ & 80 & $50-130$ & $74 \pm 11$ & 74 & $48-120$ & $<0.0001$ \\
\hline VAT $(\mathrm{mm})$ & $34 \pm 19$ & 30 & $0-100$ & $40 \pm 19$ & 38 & 3-100 & $27 \pm 17$ & 23 & $0-100$ & $<0.0001$ \\
\hline SAT $(\mathrm{mm})$ & $13 \pm 7$ & 12.5 & $1-91$ & $12 \pm 6$ & 12 & $1-91$ & $14 \pm 7$ & 13 & $1-83$ & $<0.0001$ \\
\hline $\begin{array}{l}\text { 1stCC-IMT } \\
(\mathrm{mm})^{(\mathrm{a})}\end{array}$ & $0.71 \pm 0.16$ & 0.69 & $0.45-2.11$ & $0.73 \pm 0.16$ & 0.70 & $0.45-1.70$ & $0.69 \pm 0.15$ & 0.67 & $0.47-2.11$ & 0.003 \\
\hline $\begin{array}{l}\text { IMT mean } \\
(\mathrm{mm})^{(\mathrm{a})}\end{array}$ & $0.68 \pm 0.13$ & 0.65 & $0.46-1.58$ & $0.69 \pm 0.16$ & 0.67 & $0.48-1.57$ & $0.67 \pm 0.12$ & 0.64 & $0.46-1.27$ & ns \\
\hline $\begin{array}{l}\mathbf{I M T}_{\max } \\
(\mathrm{mm})^{(\mathbf{a})}\end{array}$ & $0.98 \pm 0.30$ & 0.91 & $0.57-4.31$ & $1.01 \pm 0.33$ & 0.93 & $0.60-2.96$ & $0.94 \pm 0.28$ & 0.90 & $0.57-4.31$ & 0.006 \\
\hline $\begin{array}{l}\text { IMT mean-max } \\
(\mathrm{mm})^{(\mathrm{a})}\end{array}$ & $1.10 \pm 0.35$ & 0.99 & $0.63-3.46$ & $1.14 \pm 0.37$ & 1.02 & $0.63-2.69$ & $1.07 \pm 0.33$ & 0.98 & $0.66-3.46$ & 0.004 \\
\hline $\begin{array}{l}\text { ICCAD } \\
(\mathrm{mm})^{(\mathrm{a})}\end{array}$ & $7.15 \pm 0.75$ & 7.07 & $5.20-10.2$ & $7.45 \pm 0.70$ & 7.30 & $5.90-9.82$ & $6.87 \pm 0.68$ & 6.82 & $5.20-10.2$ & $<0.0001$ \\
\hline
\end{tabular}

511

BMI: body mass index; SBP: systolic blood pressure; DBP: diastolic blood pressure; VAT: Visceral Adipose Tissue; SAT:

Subcutaneous Adipose Tissue, IMT: intima-media caritud artery thickness; ICCAD: interadventitia common carotid artery diameter.

(a) These measurements were carried out by US in 804 subjects (394 men, 410 women) who were selected according to a 1:3 random assignment procedure, according to the study protocol 
Table 2. Baseline biochemical and haematological characteristics of the CA.ME.LI.A study population

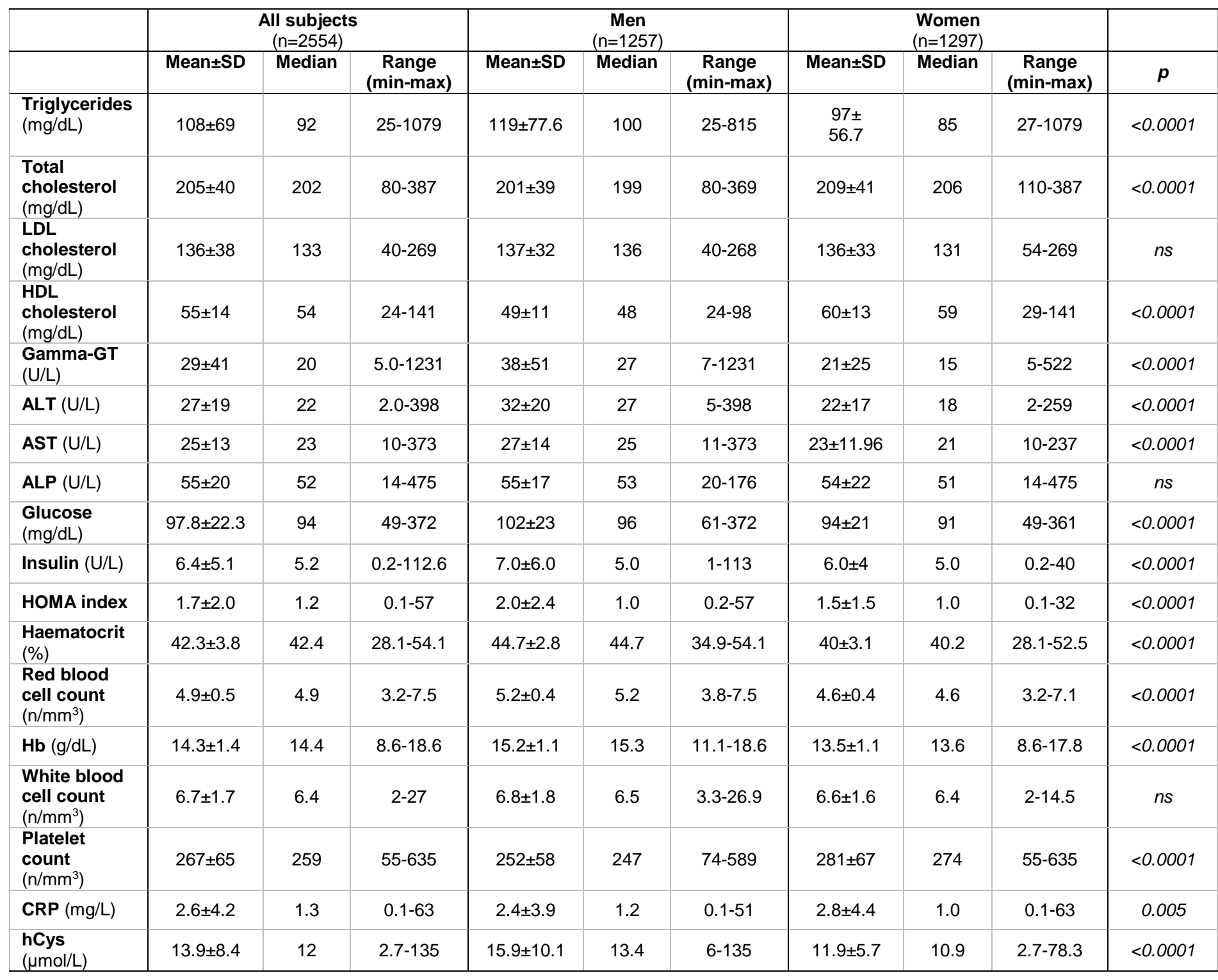


Table 3. Habits, personal disease, and family history in the CA.ME.LI.A study population

\begin{tabular}{|c|c|c|c|c|c|}
\hline & & $\begin{array}{c}\text { All subjects } \\
(n=2554)\end{array}$ & $\begin{array}{c}\text { Men } \\
(n=1257)\end{array}$ & $\begin{array}{l}\text { Women } \\
(n=1297)\end{array}$ & $p$ \\
\hline \multirow{3}{*}{$\begin{array}{l}\text { Smoking } \\
\text { habits }\end{array}$} & Smoker & $652(26 \%)$ & $372(30 \%)$ & $280(21 \%)$ & \multirow{3}{*}{$<0.0001$} \\
\hline & Former smoker & $596(23 \%)$ & $380(30 \%)$ & $216(17 \%)$ & \\
\hline & Non-smoker & 1306 (51\%) & $505(40 \%)$ & $801(62 \%)$ & \\
\hline \multirow{3}{*}{$\begin{array}{l}\text { Drinking } \\
\text { habits }^{(a)}\end{array}$} & Drinker & $1456(59 \%)$ & $918(75 \%)$ & $538(43 \%)$ & \multirow{3}{*}{$<0.0001$} \\
\hline & Former drinker & $48(2 \%)$ & $27(2 \%)$ & $21(2 \%)$ & \\
\hline & Non-drinker & 960 (39\%) & $272(22 \%)$ & $699(55 \%)$ & \\
\hline $\begin{array}{l}\text { Life } \\
\text { style }\end{array}$ & $\begin{array}{l}\text { Sedentary } \\
\text { behaviour }\end{array}$ & 1098 (43\%) & $515(41 \%)$ & $583(45 \%)$ & \\
\hline \multirow{9}{*}{$\begin{array}{l}\text { Personal } \\
\text { history } \\
\text { of } \\
\text { disease }\end{array}$} & Diabetes & $173(7 \%)$ & $110(9 \%)$ & $63(5 \%)$ & $<0.0001$ \\
\hline & $\begin{array}{l}\text { Cardiovascular } \\
\text { disease }\end{array}$ & $215(8 \%)$ & $118(9 \%)$ & 97 (7\%) & ns \\
\hline & Coronary & $86(3 \%)$ & $58(5 \%)$ & $28(2 \%)$ & 0.0006 \\
\hline & Cerebrovascular & $36(1 \%)$ & $19(2 \%)$ & $17(1 \%)$ & ns \\
\hline & Peripheral artery & $93(4 \%)$ & $41(3 \%)$ & $52(4 \%)$ & ns \\
\hline & Hypertension & $587(23 \%)$ & $297(24 \%)$ & $290(22 \%)$ & $n s$ \\
\hline & Liver disease & 759 (72\%) & $431(65 \%)$ & $328(84 \%)$ & $<0.0001$ \\
\hline & $\begin{array}{l}\text { Chronic renal } \\
\text { failure }\end{array}$ & 204 (8\%) & $114(9 \%)$ & $91(7 \%)$ & ns \\
\hline & Cancer & $100(4 \%)$ & $37(4 \%)$ & $63(5 \%)$ & 0.01 \\
\hline \multirow{5}{*}{$\begin{array}{l}\text { Family } \\
\text { history }\end{array}$} & Diabetes & $673(2 \%)$ & $322(26 \%)$ & $351(27 \%)$ & $n s$ \\
\hline & $\begin{array}{l}\text { Cardiovascular } \\
\text { disease }\end{array}$ & 1070 (42\%) & 496 (39\%) & 574 (44\%) & 0.014 \\
\hline & Hypertension & 1385 (54\%) & $598(48 \%)$ & $787(61 \%)$ & $<0.0001$ \\
\hline & NAFLD & $134(5.2 \%)$ & $62(4.9 \%)$ & $72(5.6 \%)$ & 0.53 \\
\hline & HBV/HCV infection & 732 (29\%) & $106(8.4 \%)$ & $131(10 \%)$ & 0.15 \\
\hline
\end{tabular}

Drinker was defined as an individual consuming $>24 \mathrm{~g} /$ day of ethanol for men and $12 \mathrm{~g} /$ day for women. 
Table 4. Metabolic syndrome and its diagnostic criteria in the CA.ME.LI.A study population

\begin{tabular}{|r|c|c|c|}
\hline & All subjects $(n=2554)$ & $\begin{array}{c}\text { Men } \\
(n=1257)\end{array}$ & $\begin{array}{c}\text { Women } \\
(n=1297)\end{array}$ \\
\hline Metabolic syndrome ${ }^{(a)}$ & $596(23.3 \%)$ & $408(32.7 \%)$ & $188(14.5 \%)$ \\
\hline High waist circumference & $950(37.2 \%)$ & $346(27.5 \%)$ & $604(46.6 \%)$ \\
\hline Glucose intolerance & $752(49.5 \%)$ & $486(38.7 \%)$ & $266(20.5 \%)$ \\
\hline Low HDL values & $513(20.1 \%)$ & $235(18.7 \%)$ & $278(21.5 \%)$ \\
\hline High triglyceride values & $421(16.5 \%)$ & $272(21.6 \%)$ & $149(11.5 \%)$ \\
\hline Hypertension & $859(33.6 \%)$ & $467(37.1 \%)$ & $<0.0001$ \\
\hline
\end{tabular}
or more of the following: waist circumference $\geq 102 \mathrm{~cm}(\mathrm{M})$ or $\geq 88 \mathrm{~cm}(\mathrm{~F})$; fasting glucose $\geq 100 \mathrm{mg} / \mathrm{dL}$, fasting HDL $<40 \mathrm{mg} / \mathrm{dL}$ (M) or $<50 \mathrm{mg} / \mathrm{dL}$ $(\mathrm{F}$ ), fasting triglyceride $\mathrm{s} \geq 150 \mathrm{mg} / \mathrm{dL}$, hypertension (systolic $>140 \mathrm{mmHg}$, diastolic blood pressure $>90 \mathrm{mmHg}$ ) 
Figure 1. (A) Stratification of the CA.ME.LI.A population as a function of BMI classes defined by WHO. (B) Stratification of the CA.ME.LI.A population as a function of fatty liver diseases. In the figure, the stratification is represented both for the whole population and separated by sex. The numbers over the column indicate the percentage of subjects within the class. In Tables S3 (BMI) and S6 (liver disease) are reported the numeric values and the statistical significance, which was calculated by Fisher exact test. All the comparisons are significant between men and women except for the prevalence of OFLD.

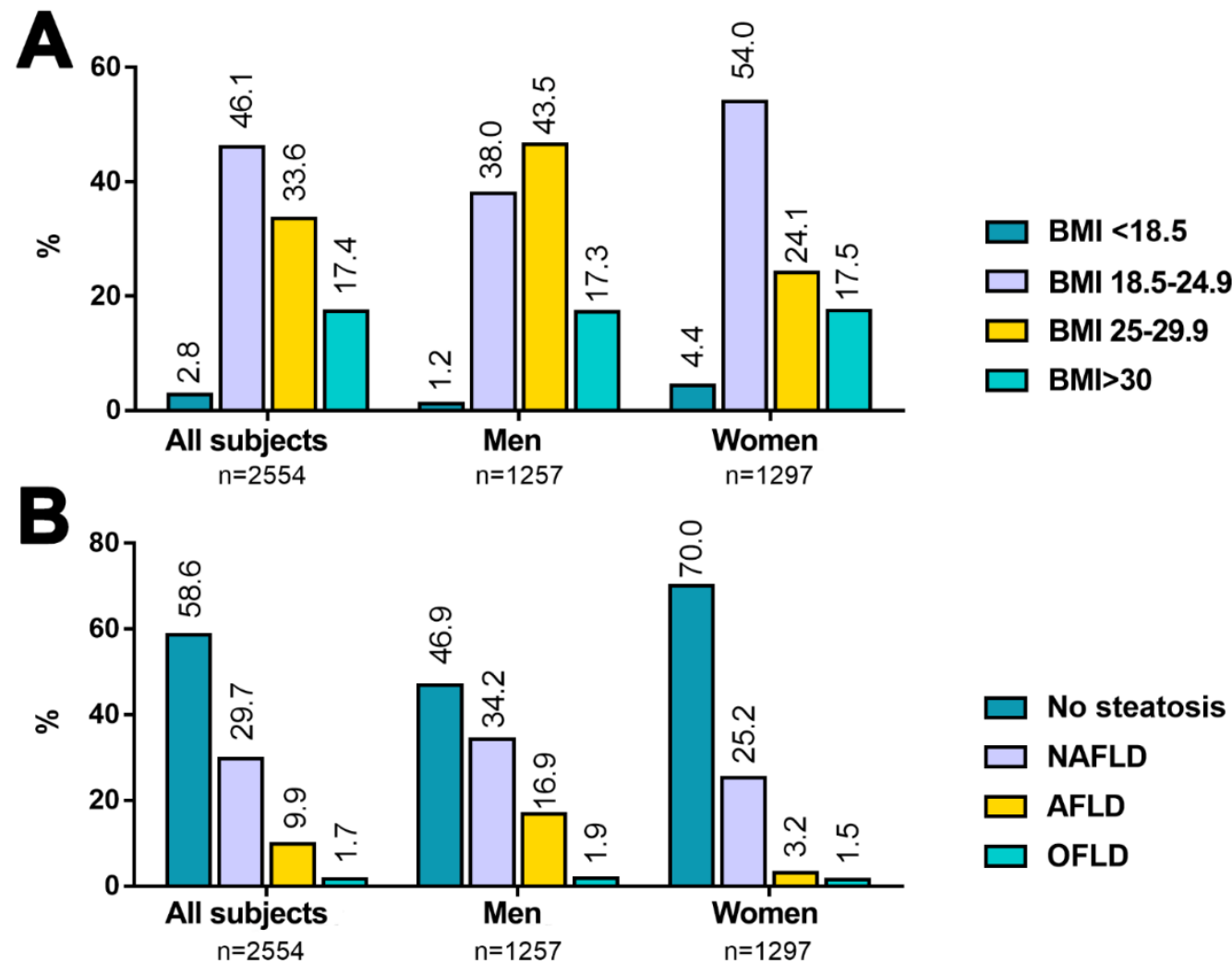

559 
569

570

571

572
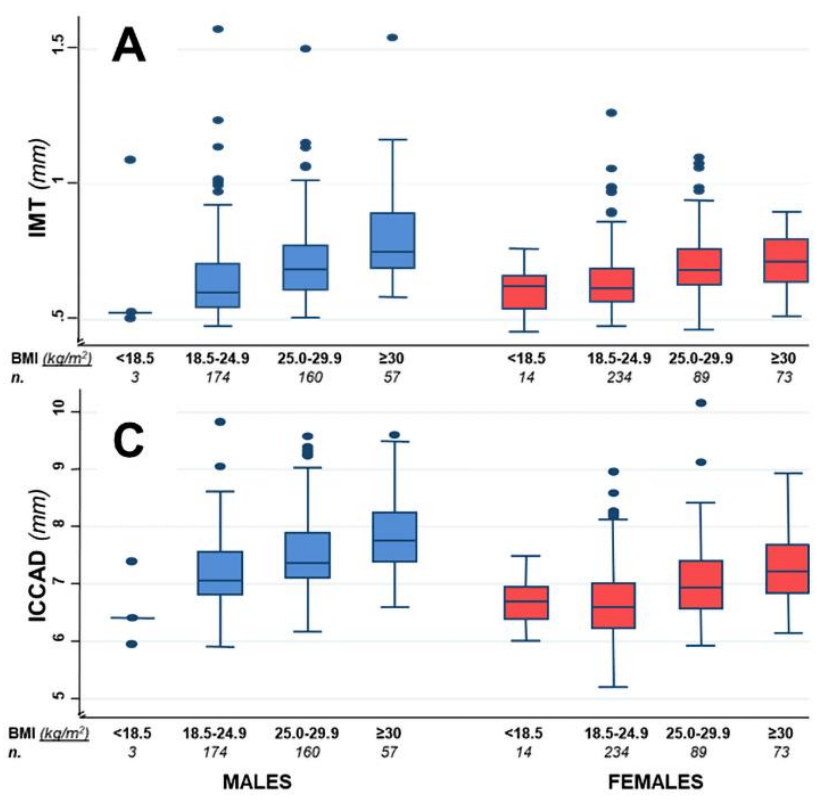
in the male and female population.

Figure 2. Values of carotid intima median thickness (IMT) and inter-adventitia common carotid artery diameter (ICCAD) according to BMI class $(A, C)$ in the male and female population. Values of carotid intima median thickness (IMT) and inter-adventitia common carotid artery diameter (ICCAD) according to age class (B,D)
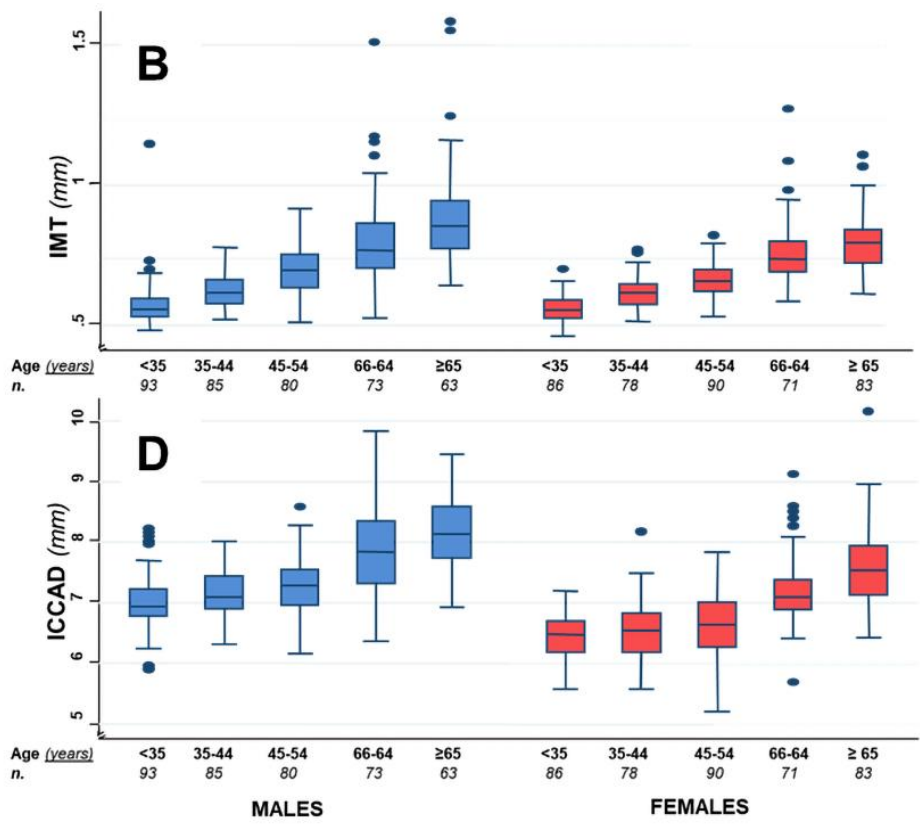


\section{Reviewer \#1: COMMENTS}

In this manuscript the authors aim to characterize the prevalence of cardiovascular risk factors, metabolic syndrome, liver and autoimmune diseases in the general adult population participating in the CA.ME.LI.A study, which is an epidemiological study performed 2009-2011 in Northern Italy. I do believe that the paper by Bignotto et al. is well structured and offers an extensive amount of interesting experimental data about the baseline characteristics of a large population from Northern Italy. It's true that this presentation is limited to some associations between metabolic and clinical risk factors for cardiovascular diseases; but the authors claims clearly that many other correlations, stratification and linkage can be further investigated, and they aim to do it in the immediate future. For example, it is worth noting the relationship between the inflammation marker CRP and both gender and BMI.

Reply: We are sincerely thankful for your comments. Please find enclosed the point-by-point rebuttal to your interesting observations.

I have some minor suggestions that might improve the manuscript:

Please the authors should include the figure S1 in the Supplementary Materials.

Reply: We amended accordingly.

Could the authors clarify the last sentence on pag. 4 ?

Reply: We reformatted the sentence you kindly indicated and we checked the language throughout the paper (i.e. line 48, 59,85,91,111,216, 229, 252, 274, 336 marked in yellow).

The authors should elucidate the significance of the statistic tests in Ffigures 1 (panel $A, B$ ) and 2. The captions of the figures should also report the association with the Supplementary Tables they derive from.

Reply: We thank the Reviewer for the precious advice. We added in the caption of figure 1 the following sentence: "In Tables S3 (BMI) and S6 (liver disease) are reported the numeric values and the statistical significance, which was calculated by Fisher exact test. All the comparisons are significant between men and women except for the prevalence of OFLD"

The authors should claim that CRP could not be evaluated with the high sensitivity assay.

Reply: Thank you for this comment. Now, it is claimed accordingly in Materials and Methods Section.

In addition, we have fully revised the literature, correcting some mistakes and adding some new and very relevant references. 
Click here to access/download e-components

Supplementary materials Camelia 2021-01-29.docx 


\title{
CA.ME.LI.A. An epidemiological study on the prevalence of cardiovascular, metabolic, liver and autoimmune diseases in Northern Italy
}

\author{
Monica Bignotto ${ }^{\mathrm{a}^{*}}$, Michele Dei Cas $^{\mathrm{b}^{*}}$, Rita Paroni ${ }^{\mathrm{b}}$, Elena Biancoa, Paola Zermiani ${ }^{\mathrm{a}}$, Maria Grazia \\ Gangale ${ }^{c}$, Valentina Zadro ${ }^{a}$, Margherita Maregattia ${ }^{a}$ Alessandra Piagnani ${ }^{a}$, Antonio Russo ${ }^{d}$, \\ Damiano Baldassarre ${ }^{e, f}$, Franco Follig,h, Pier Maria Battezzatia,h, Massimo Zuin ${ }^{\text {a,h }}$
}

a Liver and gastroenterology Unit, Department of Health Sciences, Universita' degli Studi di Milano, Milan, Italy

b Clinical Biochemistry and Mass Spectrometry, Department of Health Sciences, Universita' degli Studi di Milano, Milan, Italy

${ }^{c}$ ASST Ovest Milanese, via Papa Giovanni Paolo II, Legnano, Milan, Italy

${ }^{d}$ Epidemiology Unit, Agency for Health Protection of Milan, Corso Italia 19, 20122, Milan, Italy

e Department of Medical Biotechnology and Translational Medicine, Università degli Studi di Milano, Milan, Italy

f Centro Cardiologico Monzino, IRCCS, Milan, Italy

g Endocrinology and Metabolism, Department of Health Sciences, Universita' degli Studi di Milano, Milan, Italy

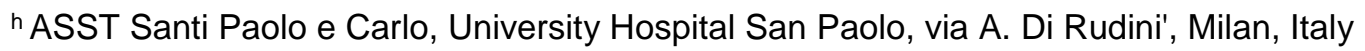

${ }^{*} \mathrm{MB}$ and MDC equally contributed to the paper

Corresponding authors: Massimo Zuin, Internal Medicine and Liver Unit (massimo.zuin@unimi.it) and Franco Folli (franco.folli@unimi.it) Endocrinology and Metabolism Dipartimento di Scienze della Salute, Universita' degli Studi di Milano, via A. di Rudinì,8, 20142, Milan, Italy. Tel. +390250323192

\section{HIGHLIGHTS}

- CA.ME.LI.A is an epidemiological study on the population of Abbiategrasso (Italy)

- To identify metabolic and clinical risk factors for heart and liver diseases

- With a randomization criterion (1:6) 1257 men and 1297 women 18-77y were enrolled

- Overweight, obesity, triglycerides, cholesterol, $\gamma$-GT, glucose were higher in men

- $\mathrm{HDL}, \mathrm{CRP}$ and prevalence of $\mathrm{CRP}>5.0 \mathrm{mg} / \mathrm{L}$ were higher in women than in men 
Click here to access/download e-components MM_coi_disclosure.pdf 
Click here to access/download e-components MZ_coi_disclosure.pdf 
Click here to access/download e-components PB_coi_disclosure.pdf 
Click here to access/download e-components PZ_coi_disclosure Copy.pdf 
Click here to access/download e-components RP_coi_disclosure.pdf 
Click here to access/download e-components VZ_coi_disclosure.pdf 
Click here to access/download e-components AP_coi_disclosure.pdf 
Click here to access/download e-components AR_coi_disclosure.pdf 
Click here to access/download

\section{e-components \\ DB_coi_disclosure.pdf}


Click here to access/download e-components EB_coi_disclosure.pdf 
Click here to access/download e-components FF_coi_disclosure.pdf 
Click here to access/download e-components MDC_coi_disclosure.pdf 
Click here to access/download e-components MGG_coi_disclosure.pdf 